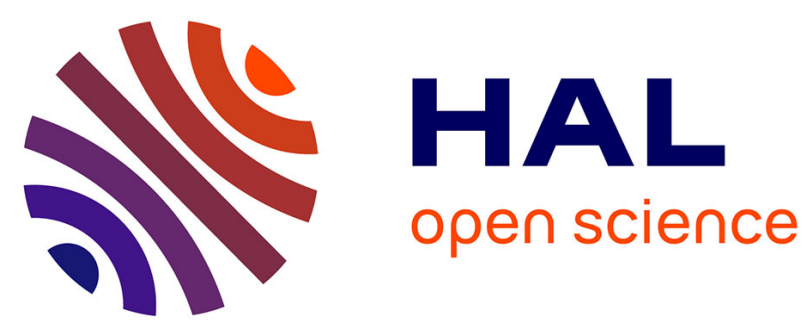

\title{
Pulsed liquid-injection MOCVD of high-K oxides for advanced semiconductor technologies
}

C. Dubourdieu, Hervé Roussel, Carmen Jiménez, M. Audier, J. P. Senateur, S. Lhostis, L. Auvray, F. Ducroquet, B. J. O'Sullivan, P. K. Hurley, et al.

\section{- To cite this version:}

C. Dubourdieu, Hervé Roussel, Carmen Jiménez, M. Audier, J. P. Senateur, et al.. Pulsed liquidinjection MOCVD of high-K oxides for advanced semiconductor technologies. Materials Science and Engineering: B, 2005, B118 (1-3), pp.105-111. 10.1016/j.mseb.2004.12.019 . hal-00012501

\section{HAL Id: hal-00012501 \\ https://hal.science/hal-00012501}

Submitted on 9 Jul 2021

HAL is a multi-disciplinary open access archive for the deposit and dissemination of scientific research documents, whether they are published or not. The documents may come from teaching and research institutions in France or abroad, or from public or private research centers.
L'archive ouverte pluridisciplinaire HAL, est destinée au dépôt et à la diffusion de documents scientifiques de niveau recherche, publiés ou non, émanant des établissements d'enseignement et de recherche français ou étrangers, des laboratoires publics ou privés. 


\title{
Pulsed liquid-injection MOCVD of high-K oxides for advanced semiconductor technologies
}

\author{
C. Dubourdieu ${ }^{\mathrm{a}, *}$, H. Roussel ${ }^{\mathrm{a}}$, C. Jimenez ${ }^{\mathrm{a}}$, M. Audier ${ }^{\mathrm{a}}$, J.P. Sénateur ${ }^{\mathrm{a}}$, S. Lhostis ${ }^{\mathrm{a}, \mathrm{b}}$, \\ L. Auvray ${ }^{\mathrm{a}}$, F. Ducroquet ${ }^{\mathrm{c}}$, B.J. O'Sullivan ${ }^{\mathrm{d}}$, P.K. Hurley ${ }^{\mathrm{d}}$, S. Rushworth ${ }^{\mathrm{e}}$, L. Hubert-Pfalzgraf ${ }^{\mathrm{f}}$ \\ a Laboratoire des Matériaux et du Génie Physique, UMR CNRS 5628, ENSPG BP46, 38402 St. Martin d'Hères, France \\ ${ }^{b}$ STMicroelectronics, 850 rue Jean Monnet, 38926 Crolles Cedex, France \\ ${ }^{\mathrm{c}}$ Laboratoire de Physique de la Matière, UMR CNRS 5511, INSA Lyon, 69621 Villeurbanne, France \\ ${ }^{\mathrm{d}}$ NMRC, Lee Maltings, Prospect Row, Cork, Ireland \\ e Epichem Oxides and Nitrides, 25 James Carter Road, Mildenhall, Suffolk IP287 DE, UK \\ ${ }^{\mathrm{f}}$ Institut de Recherche sur la Catalyse, UPR CNRS 5401, 2 av A. Einstein, 69626 Villeurbanne, France
}

\begin{abstract}
$\mathrm{HfO}_{2}$ and $\mathrm{SrTiO}_{3}$ films were grown on silicon by liquid injection metal organic chemical vapour deposition. The microstructure and structure of the films were characterised by X-ray and electron diffraction, X-ray reflectometry, infrared spectroscopy, and microscopy techniques. In both cases, we emphasised the role of precursors in the resulting composition and microstructure of the films. Dense films of $\mathrm{HfO}_{2}$, either amorphous or crystalline depending on the deposition temperature, were synthesised using $\mathrm{Hf}\left(\mathrm{O}^{t} \mathrm{Bu}\right)_{2}(\mathrm{mmp})_{2}$ precursor. Permittivity values of 14-19 were obtained, consistent with the monoclinic structure determined from X-ray diffraction. Optimised films exhibit breakdown field of $6 \mathrm{MV} \mathrm{cm}^{-1}$ and leakage current densities as low as $10^{-8} \mathrm{~A} \mathrm{~cm}^{-2}$ at $1 \mathrm{~V}$.

Polycrystalline $\mathrm{SrTiO}_{3}$ films were grown using either a mixture of precursors or a heterometallic precursor. The heterometallic precursor provides some advantages such as a lowering of the crystallisation temperature of the perovskite-type phase and a reduction of carbonate impurities at low temperatures. It also allows to keep the films composition constant over a wide temperature range $\left(550-750{ }^{\circ} \mathrm{C}\right)$. The films are highly textured with $\left[\begin{array}{lll}0 & 0 & 1\end{array}\right]_{\mathrm{SrTiO}_{3}}$ parallel to $\left[\begin{array}{lll}0 & 0 & 1\end{array}\right]_{\mathrm{Si}}$. The permittivity depends strongly on the films thickness $\left(\varepsilon_{\mathrm{r}} \sim 30\right.$ for $10 \mathrm{~nm}$ and $\varepsilon_{\mathrm{r}} \sim 100$ for $100 \mathrm{~nm}$ ). An equivalent oxide thickness of $1.36 \mathrm{~nm}$ (for physical thickness of $15.0 \mathrm{~nm}$ ) was obtained for optimised $\mathrm{SrTiO}_{3}$ film, with a leakage current density of $10^{-2} \mathrm{Ac} \mathrm{m}^{-2}$ at $1 \mathrm{~V}$.
\end{abstract}

Keywords: High permittivity oxide; MOCVD; Heterometallic; Microstructure

\section{Introduction}

High dielectric permittivity oxides are currently widely investigated for the replacement of the gate insulator $\mathrm{SiO}_{2}$ in advanced complementary metal-oxide-semiconductor (CMOS) devices. Indeed, silica-based transistor technology is approaching fundamental limits as the oxide thickness is reduced below $2 \mathrm{~nm}$ (direct tunnel current effect and reliability problems) [1]. Many oxides exhibit a permittivity higher than that of $\mathrm{SiO}_{2}$ but their integration requires to consider many other issues, such as thermal stability with $\mathrm{Si}$ or with $\mathrm{SiO}_{2}$,

\footnotetext{
* Corresponding author. Tel.: +33 476826 455; fax: +33 476826394

E-mail address: catherine.dubourdieu@inpg.fr (C. Dubourdieu).
}

control of the interfacial layer, stability of the microstructure upon high-temperature processing and compatibility with the poly-Si gate. $\mathrm{HfO}_{2}$ is the most studied dielectric material for advanced microelectronics applications since 2001 (if one refers to the number of publications in this field). It exhibits a medium permittivity, which is often given to be 15-20 in the bulk material (supposedly monoclinic). $\mathrm{HfO}_{2}$ is stable on $\mathrm{Si}$, which is an important requirement to achieve a low equivalent oxide thickness (EOT) and to obtain a stable CMOS structure after full processing. $\mathrm{HfO}_{2}$ or hafnium silicate are currently the most probable materials to be used, if ever, in a CMOS circuit. For longer-term application purposes, very high permittivity materials $(>300)$ encountered in the perovskite-type compounds such as $\mathrm{SrTiO}_{3}$ are attractive. 
$\mathrm{SrTiO}_{3}$ has been widely studied for many applications such as tunable microwave devices $[2,3]$ or high-density dynamic random access memory (DRAM) devices [4]. The epitaxy of $\mathrm{SrTiO}_{3}$ on $\mathrm{Si}$ by molecular beam epitaxy and the possible interface engineering with $(\mathrm{AO})_{n}\left(\mathrm{~A}^{\prime} \mathrm{BO}_{3}\right)_{m}$ compounds were demonstrated [5-8]. An EOT of $5.4 \AA$ was reported in a MOS structure based on $\mathrm{SrTiO}_{3}$ as gate oxide [8]. $\mathrm{SrTiO}_{3}$ could thus be of interest to get EOTs below $1 \mathrm{~nm}$, which is more difficult to achieve with medium-к oxides.

Concerning the deposition technique, no consensus prevails so far. Chemical vapour deposition from metal organic precursors (MOCVD) and atomic layer deposition (ALD) are widely used among the different groups involved in this research field. These techniques are suitable for industrial scale production on large surfaces and allow for conformal coverage. For multi-elements oxides such as $\mathrm{SrTiO}_{3}$, ALD and classical MOCVD are more difficult to apply since the metal organic precursors used for strontium (usually $\beta$-diketonates derivatives) are not highly volatile and tend to decompose. Innovative CVD techniques such as liquid injection MOCVD [9] allow one to solve such issues and to grow reproducibly functional oxides with nanometer-scale control of the thickness [10]. These chemical routes to grow high-K materials require adequate precursors. For CVD process, metalorganic precursors are widely used because of higher volatility at lower evaporation temperature as compared to halides. The growth of $\mathrm{HfO}_{2}$ by MOCVD was carried out so far mostly by using the alkoxide $\mathrm{Hf}\left[\mathrm{OC}\left(\mathrm{CH}_{3}\right)_{3}\right]_{4}$ precursor (also written $\left.\mathrm{Hf}\left(\mathrm{O}^{t} \mathrm{Bu}\right)_{4}\right)$ [11-15]. Other molecules such as the alkoxide $\mathrm{Hf}\left(\mathrm{O}-i-\mathrm{C}_{3} \mathrm{H}_{7}\right)_{4}[16]$ or the tetrakis diethyl amino hafnium (TDEAH) $\mathrm{Hf}\left[\left(\mathrm{C}_{2} \mathrm{H}_{5}\right)_{2} \mathrm{~N}\right]_{4}$ [17-19] have been also reported. The amine has the advantage of containing no oxygen however, it is extremely sensitive to air and thus delicate to handle. The $\mathrm{Hf}\left(\mathrm{O}^{t} \mathrm{Bu}\right)_{2}(\mathrm{mmp})_{2}$ was recently proposed and its synthesis and use in a MOCVD process is described by Williams et al. [20] ( $\mathrm{mmp}=$ methoxymethyl2-propanol with formula $\left.\mathrm{OC}\left(\mathrm{CH}_{3}\right)_{2} \mathrm{CH}_{2} \mathrm{OCH}_{3}\right)$. This compound was also tested for ALD deposition [21]. For $\mathrm{SrTiO}_{3}$ synthesis by MOCVD, the $\beta$-diketonates $\mathrm{Sr}(\mathrm{tmhd})_{2}$ and $\mathrm{Ti}\left(\mathrm{O}^{i} \mathrm{Pr}\right)_{2}$ (tmhd $)_{2}$ are widely used (tmhd stands for 2,26,6-tetramethylheptanedionate with formula $\left.\mathrm{C}_{11} \mathrm{H}_{19} \mathrm{O}_{2}\right)$ ) ( $\mathrm{O}^{i} \mathrm{Pr}$ stands for iso-propoxide with formula: $\mathrm{CH}\left(\mathrm{CH}_{3}\right)_{2}$ ). The $\mathrm{Sr}(\mathrm{tmhd})_{2}$ is thermally unstable and thus justifies the use of flash evaporation systems such as the liquid injection source [9]. Heterometallic precursors, in which the two metal $\mathrm{Sr}$ and $\mathrm{Ti}$ elements are present in the same molecule, have been also proposed. Potential advantage of a heterometallic precursor compared to a mixture of two precursors is that the stoichiometry in solution is fixed and therefore reproducible. Also, heterometallic precursors are likely to be more volatile than the trimer $\operatorname{Sr}(\mathrm{tmhd})_{2}$. There exist several heterometallic compounds of $\mathrm{Sr}$ and $\mathrm{Ti}$ such as $\left[\mathrm{SrTi}_{2}(\mathrm{OEt})_{10}(\mathrm{EtOH})_{5}\right]_{n}, \mathrm{Sr}_{2}$ $\left.\mathrm{Ti}(\mathrm{OEt})_{8}(\mathrm{EtOH})_{5}\right]_{n}, \quad\left[\mathrm{Sr}_{2} \mathrm{Ti}\left(\mathrm{O}^{i} \mathrm{Pr}\right)_{8}\left({ }^{i} \mathrm{PrOH}\right)_{5}\right]_{n}, \quad \mathrm{Sr}_{6} \mathrm{Ti}_{4} \mathrm{O}_{4}$ $\left(\mathrm{O}^{i} \mathrm{Pr}\right)_{20}$ or $\mathrm{SrTi}_{4}(\mathrm{OEt})_{18}$. Information on their syntheses and products characterisation can be found in [22-24]. Among the above mentioned one, the Sr:Ti stoichiometry is different from 1 . The heterometallic alkoxide $\left[\mathrm{Sr}_{2} \mathrm{Ti}\left(\mathrm{O}^{i} \mathrm{Pr}\right)_{8}\left({ }^{i} \mathrm{PrOH}\right)_{5}\right]$ is for example used for the synthesis of $\mathrm{Sr}_{2} \mathrm{TiO}_{4}$ [22]. In order to grow $\mathrm{SrTiO}_{3}$, a Sr:Ti ratio of 1 should be present in the precursor. The only known molecules are those reported by Hubert-Pfalzgraf et al. $[25,26] . \mathrm{Sr}_{2} \mathrm{Ti}_{2}(\mathrm{tmhd})_{4}\left(\mathrm{O}^{i} \mathrm{Pr}\right)_{8}$ [26] appears more stable than the parent molecule with the ligand OEt.

In this paper, we present the growth by liquid-injection MOCVD and the characterisation of two different high dielectric permittivity oxides, $\mathrm{HfO}_{2}$ and $\mathrm{SrTiO}_{3}$, synthesised on $\mathrm{Si} / \mathrm{SiO}_{2}$ substrates. In both cases, we emphasise the role of precursors in the resulting composition and microstructure of the films. Effects of process parameters (substrate's temperature or total pressure) on the microstructure are also discussed. Finally, optimised electrical properties are presented.

\section{Experimental}

The films were grown by pulsed liquid injection metal organic chemical vapour deposition (MOCVD). In this delivery scheme, the liquid precursor is introduced in micro-amounts (few $\mu$ l) in the evaporator by means of a microvalve (car injector) [9] and a non-contact flash evaporation occurs, while the rest of the solution is kept at room temperature under an inert gas. Thus precursors of poor stability can be used, such as the $\beta$-diketonates of $\mathrm{Sr}$ or $\mathrm{Ba}$. The amount of injected liquid depends on several parameters: the injection opening time, the injection frequency, the solution viscosity and the differential pressure between the liquid reservoir and the evaporator. After flash evaporation, the reactive species are transported toward the reaction zone by a carrier gas such as argon (a positive temperature gradient is set in order to avoid any condensation of the precursors during the transport).

\section{1. $\mathrm{HfO}_{2}$ films deposition}

$\mathrm{HfO}_{2}$ films were grown on $100 \mathrm{~mm} \mathrm{Si}$ wafers. The substrates can be loaded via a separate chamber that is pumped down before the transfer to the deposition chamber (both are stainless steel chambers). The substrate's holder is a SiCcovered graphite block heated by $4 \times 1 \mathrm{~kW}$ lamps. The temperature of the Si wafer is measured by a pyrometer, which has been calibrated by means of a thermocouple embedded in a silicon substrate. In this set-up, the precursor liquid flow rate is monitored by an optical method, so that the reactive species flow rate can be controlled in real time. The reactive gas flows downward to the substrate's plate (the reactor walls are thermalised). The deposited thickness is monitored in situ by laser reflectometry on the film's surface $(\lambda=640 \mathrm{~nm})$.

The substrates were n-type silicon wafers $(2-4 \Omega \mathrm{cm}$ resistivity) prepared with a standard FSIB clean. Three different precursors (provided by Epichem) were used: $\mathrm{Hf}\left(\mathrm{O}^{t} \mathrm{Bu}\right)_{4}, \quad \mathrm{Hf}\left(\mathrm{O}^{t} \mathrm{Bu}\right)_{2}(\mathrm{dmae})_{2}$ and $\mathrm{Hf}\left(\mathrm{O}^{t} \mathrm{Bu}\right)_{2}(\mathrm{mmp})_{2}$ $\left(\right.$ dmae $=$ dimethylaminoethoxide with formula $\mathrm{OCH}_{2} \mathrm{CH}_{2} \mathrm{~N}$ 
$\left.\left.\left(\mathrm{CH}_{3}\right)_{2}\right)\right)$. They were dissolved with $n$-hexane or with octane. Different atmospheres during deposition were studied: argon, oxygen and hydrogen. In each case, the total flow rate was $200 \mathrm{sccm}$. The working pressure was $133 \mathrm{~Pa}$ (1 Torr) and the deposition temperature was varied in the range of $250-600^{\circ} \mathrm{C}$. Selected samples were annealed in a rapid thermal annealing (RTA) system.

\section{2. $\mathrm{SrTiO}_{3}$ films deposition}

$\mathrm{SrTiO}_{3}$ films were deposited on $2 \mathrm{~cm} \times 2 \mathrm{~cm} \mathrm{Si}$ substrates. The same type of source system was used. The evaporator is connected to the reaction zone, which consists of a quartz tube, where the stainless steel substrate's holder is placed (the substrate's holder is surrounded by a cylinder heated by induction (RF)). The reactive species gas flows upward from the evaporator to the substrate. The silicon substrate is hold mechanically or pasted. Here, the injected liquid is monitored in situ by means of a pressure measurement inside the evaporator. The film's thickness is monitored in situ by laser reflectometry $(\lambda=670 \mathrm{~nm})$.

The substrates were the same as mentioned for $\mathrm{HfO}_{2}$ deposition. Different precursors were used: either a mixture of $\operatorname{Sr}(\mathrm{tmhd})_{2}$ (stabilised or not with triglyme) and $\mathrm{Ti}(\mathrm{tmhd})_{2}\left(\mathrm{O}^{i} \mathrm{Pr}\right)_{2}$ or a single heterometallic precursor $\mathrm{Sr}_{2} \mathrm{Ti}_{2}$ (tmhd) $)_{4}\left(\mathrm{O}^{i} \mathrm{Pr}\right)_{8}$ (provided by Pr. Hubert-Pfalzgraf at IRC/CNRS or by Epichem). The heterometallic precursor was originally synthesised by Hubert-Pfalzgraf et al. [26] but had not been tested so far for MOCVD applications.

These solid precursors were dissolved in octane $(0.02 \mathrm{M})$. Argon was used as a carrier gas ( $300 \mathrm{sccm})$ and oxygen as an oxidising agent $(300 \mathrm{sccm})$. The working pressure was varied in the range of $266-1333 \mathrm{~Pa}$ (2-10 Torr) and the deposition temperature was varied in the range of $450-800^{\circ} \mathrm{C}$.

\subsection{Films characterisation}

The structure and microstructure of the films were characterised by several methods: X-ray diffraction $(\theta / 2 \theta)$, X-ray reflectometry, ellipsometry, Fourier transform infra-red spectrometry (FT-IR), transmission electron microscopy (TEM) and atomic force microscopy (AFM). Electrical $C(V)$ and $I(V)$ measurements were performed (using respectively, a HP 4284A LCR meter and a HP 4156B parameter analyser for $\mathrm{HfO}_{2}$ films and HP 4284A or HP4142B systems for $\mathrm{SrTiO}_{3}$ films). MOS structures were prepared by evaporating $\mathrm{Au}$ through a shadow mask. Four different electrodes areas were prepared, ranging from $2.5 \times 10^{-5}$ to $2.3 \times 10^{-4} \mathrm{~cm}^{2}$.

\section{Results and discussion}

\subsection{Medium-к material: $\mathrm{HfO}_{2}$ films}

We investigated the effect of precursor chemistry on the final microstructure of the films. While starting with

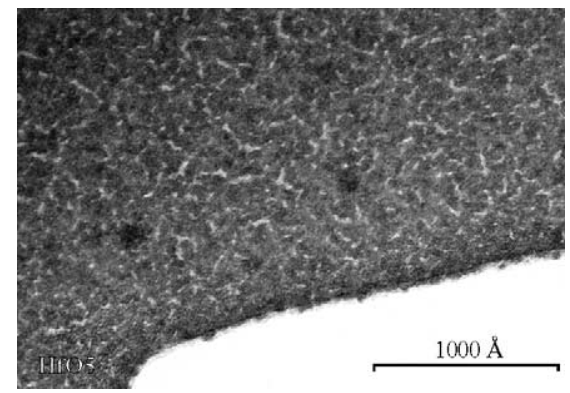

Fig. 1. Transmission electron microscopy plane view of a thin low temperature $\left(275^{\circ} \mathrm{C}\right) \mathrm{HfO}_{2}$ film deposited from $\mathrm{Hf}\left(\mathrm{O}^{t} \mathrm{Bu}\right)_{4}$ precursor on $\left(\begin{array}{lll}0 & 0 & 1\end{array}\right) \mathrm{Si} / \mathrm{SiO}_{2}$. A porous microstructure is evidenced.

$\mathrm{Hf}\left(\mathrm{O}^{t} \mathrm{Bu}\right)_{4}$, different atmospheres were used during deposition $\left(\mathrm{Ar}, \mathrm{O}_{2}, \mathrm{H}_{2}\right)$. No effect is observed on the resulting growth rate. The oxygen present in the precursor is sufficient to form $\mathrm{HfO}_{2}$. Amorphous thin films prepared from the $\operatorname{Hf}\left(\mathrm{O}^{t} \mathrm{Bu}\right)_{4}$ compound are found, however, to be porous (closed porosity) as shown by the TEM micrograph of Fig. 1 . This result is confirmed by the low refractive index determined by ellipsometry $(n<1.9)$ and by the low density determined by X-ray reflectometry $\left(8.3 \mathrm{~g} \mathrm{~cm}^{-3}\right)$. Such a porous microstructure is of course not desirable for microelectronic applications and we thus looked for other precursors. Fig. 2 shows a comparison of the growth rate, as a function of temperature, when using the precursors $\mathrm{Hf}\left(\mathrm{O}^{t} \mathrm{Bu}\right)_{2}(\mathrm{dmae})_{2}$ and $\mathrm{Hf}\left(\mathrm{O}^{t} \mathrm{Bu}\right)_{2}(\mathrm{mmp})_{2}$. The $\mathrm{Hf}\left(\mathrm{O}^{t} \mathrm{Bu}\right)_{2}(\mathrm{mmp})_{2}$ compound appears to be more appropriate for the deposition of $\mathrm{HfO}_{2}$ films as it is more volatile. Higher growth rates can be achieved with it and no accumulation of precursors is observed in the evaporator (up to $9 \mathrm{~mm}^{3}$ of solution injected/pulse). Indeed, when the precursor injection was stopped, the laser reflectance signal was constant, indicating the concomitant stop of the film's growth. On the contrary, at injection flow rates higher than $3 \mathrm{~mm}^{3} \mathrm{~s}^{-1}$ of a solution $0.05 \mathrm{moll}^{-1}$, accumulation of $\mathrm{Hf}\left(\mathrm{O}^{t} \mathrm{Bu}\right)_{2}$ (dmae $)_{2}$ precursor occurs, whatever the source

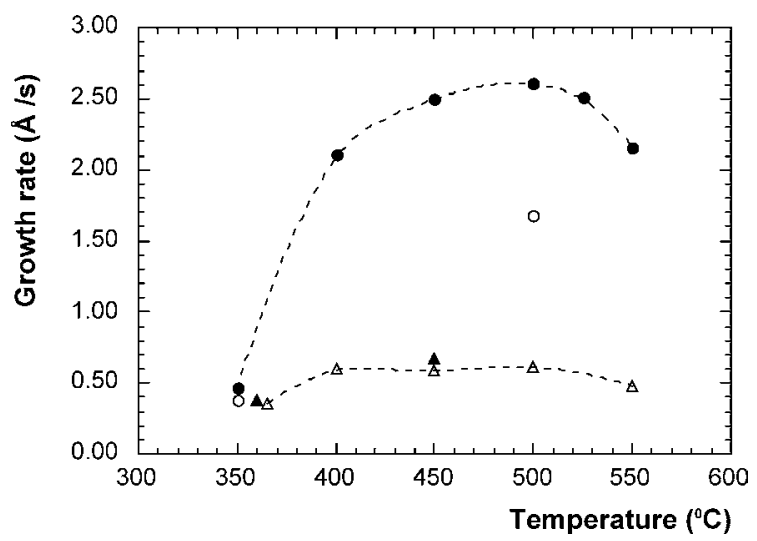

Fig. 2. Growth rates as a function of deposition temperature for $\mathrm{HfO}_{2}$ films prepared from two different precursors: $\mathrm{Hf}\left(\mathrm{O}^{t} \mathrm{Bu}\right)_{2}(\mathrm{dmae})_{2}$ (open symbols) and $\mathrm{Hf}\left(\mathrm{O}^{t} \mathrm{Bu}\right)_{2}(\mathrm{mmp})_{2}$ (closed symbols). For each precursor, two injection rates were used (circles: $9 \mathrm{~mm}^{3}$ injected/pulse and triangles: $3 \mathrm{~mm}^{3}$ injected/pulse). 
temperature. When the injection was stopped, the growth of the layer continued with a slowly decreasing growth rate (as indicated by the laser reflectance signal). Such an accumulation of condensed precursor is not acceptable for microelectronic application purposes (accumulation of precursor would lead to a non-uniform layer). In the following, we thus concentrate on films prepared from $\mathrm{Hf}\left(\mathrm{O}^{t} \mathrm{Bu}\right)_{2}(\mathrm{mmp})_{2}$. Fig. 2 indicates that, in our deposition conditions, the growth rate is maximum for a substrate temperature of about $500^{\circ} \mathrm{C}$. X-ray diffraction performed on thick films $(\sim 80 \mathrm{~nm})$ shows that the films are crystallised in the monoclinic $\mathrm{HfO}_{2}$ structure for deposition temperatures of $400{ }^{\circ} \mathrm{C}$ and above (for films grown at $350{ }^{\circ} \mathrm{C}$, the diffraction lines are very broad and hardly detected). The FTIR spectra of the crystallised films confirm the monoclinic structure of $\mathrm{HfO}_{2}$ [27], as well as the electronic diffraction. Continuous, non-porous films are obtained. AFM observations shows that both the grains size and the surface roughness are lower with the $\mathrm{Hf}\left(\mathrm{O}^{t} \mathrm{Bu}\right)_{2}(\mathrm{mmp})_{2}$ precursor as compared to the $\mathrm{Hf}\left(\mathrm{O}^{t} \mathrm{Bu}\right)_{4}$ one (respectively, RMS of $1.6 \mathrm{~nm}$ and $4.1 \mathrm{~nm}$ for $\sim 90 \mathrm{~nm}$ films). From the TEM micrographs, the interfacial layer thickness is found to remain almost unchanged after deposition, at least for films thickness up to $\sim 100 \mathrm{~nm}$. We cannot conclude about its nature (whereas, it is pure $\mathrm{SiO}_{2}$ or a Hf-silicate). However, similar experiments performed at STMicroelectronics with the same deposition technique and same precursor recently showed that no silicate and no silicide bonding was detected at the interface by X-ray photoelectron spectroscopy (Hf4f and Si2p spectra) [28].

Observations concerning the films crystallisation were also confirmed for very thin films $(<10 \mathrm{~nm})$. Fig. 3 shows the TEM micrographs of two films $(t<5 \mathrm{~nm})$ prepared at 350 and $450{ }^{\circ} \mathrm{C}$. Films grown at $350^{\circ} \mathrm{C}$ are mainly amorphous with few nanocrystallites, whereas those grown at $450^{\circ} \mathrm{C}$ are mainly crystalline (although amorphous phase remains). The fitting of the experimental X-ray reflectometry curves could be performed satisfactory using a two-layers model: an interfacial layer of $\mathrm{SiO}_{x}$ and a $\mathrm{HfO}_{2}$ layer. A good agreement was found between TEM and X-ray reflectometry for the $\mathrm{HfO}_{2}$ thickness value. The film's density determined from the fits $\left(>9.0 \mathrm{~g} \mathrm{~cm}^{-3}\right)$ also confirm the higher film's quality with the $\mathrm{Hf}\left(\mathrm{O}^{t} \mathrm{Bu}\right)_{2}(\mathrm{mmp})_{2}$ precursor. Amorphous films crystallise upon high temperature annealing under $\mathrm{Ar}$ or $\mathrm{O}_{2}$ (typically RTA at $800^{\circ} \mathrm{C}$ for $3 \mathrm{~min}$ ). Crystallisation leads to a larger surface roughness. The interfacial layer thickness increases during annealing under $\mathrm{O}_{2}$, which is detrimental for the equivalent oxide thickness value. The substrate's surface was $\mathrm{HF}$ dipped and exposed to $\mathrm{NH}_{3}$ prior to deposition $\left(670{ }^{\circ} \mathrm{C}\right.$ for $1 \mathrm{~min}$ or $950{ }^{\circ} \mathrm{C}$ for $2 \mathrm{~min}$ ) in order to investigate the effect of surface "nitridation" on the interfacial layer. Fig. 4 shows that there is no beneficial effect of such a treatment. The role of oxygen is here clearly emphasised as no interfacial growth is observed when the high-temperature annealing is performed under vacuum.

Electrical measurements were performed for selected films. Thick films $(t \geq 10 \mathrm{~nm})$ exhibit an effective dielectric permittivity in the range of 14-19 with leakage current densities as low as $10^{-8} \mathrm{~A} \mathrm{~cm}^{-2}$ at $1 \mathrm{~V}$ and breakdown fields as high as $6 \mathrm{MV} \mathrm{cm}^{-1}$. For thinner films, an equivalent oxide thickness of $3.2 \mathrm{~nm}$ for a $4.5 \mathrm{~nm}$ film was obtained. From the TEM study of the same film, the interfacial layer thickness was $1.3 \mathrm{~nm}$ (corresponding practically to the starting $\mathrm{SiO}_{2}$ layer thickness). The EOT was calculated from the maximum capacitance in accumulation mode and was not corrected for quantum mechanical or surface differential capacitance effects [29]. Lowering the initial interfacial layer thickness should allow to decrease the EOT.
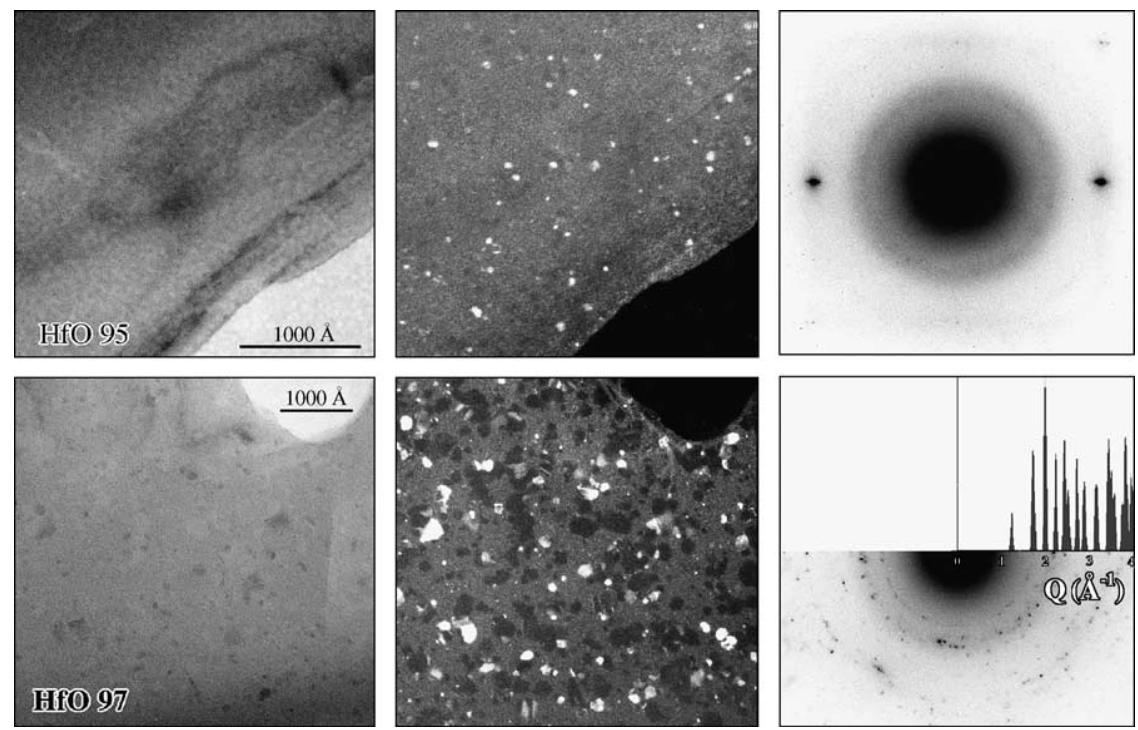

Fig. 3. Transmission electron microscopy plan views (left: bright field, right: dark field) of $\mathrm{HfO}_{2}$ thin films grown on $(001) \mathrm{Si} / \mathrm{SiO}_{2}$ at $350{ }^{\circ} \mathrm{C}(\mathrm{HfO} 95, t=3.2 \mathrm{~nm})$ and $450^{\circ} \mathrm{C}(\mathrm{HfO} 97, t=4.7 \mathrm{~nm})$ together with their electron diffraction patterns. 

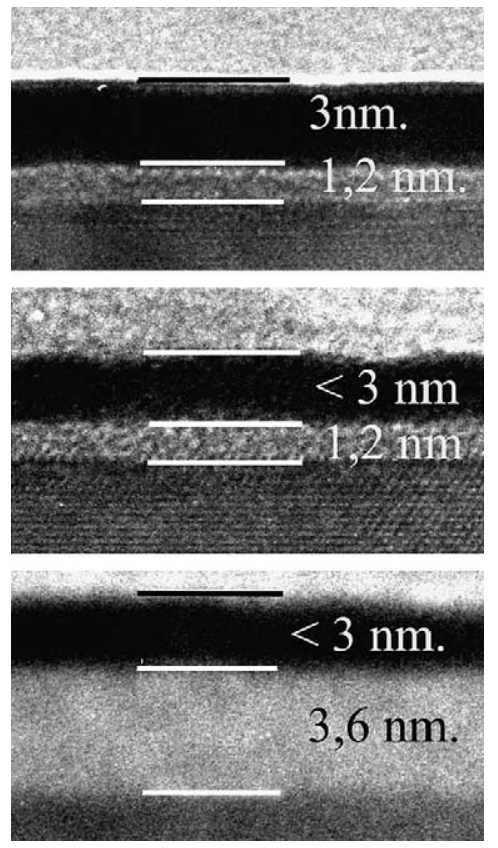

Fig. 4. High-resolution transmission electron microscopy (cross-section) of a $\mathrm{HfO}_{2}$ film deposited at $450^{\circ} \mathrm{C}$ (substrate preparation: Hf last follow by $\mathrm{NH}_{3}$ treatment at $950{ }^{\circ} \mathrm{C}$ during $2 \mathrm{~min}$ ). From top to bottom: as-deposited, after a RTA at $800^{\circ} \mathrm{C}$ for $3 \mathrm{~min}$ under high vacuum $\left(1.33 \times 10^{-4} \mathrm{~Pa}\right)$ and after a RTA at $800^{\circ} \mathrm{C}$ for 3 min under $1,01,300 \mathrm{~Pa}$ of $\mathrm{O}_{2}$.

\subsection{Very high-K material: $\mathrm{SrTiO}_{3}$ films}

For $\mathrm{SrTiO}_{3}$ deposition, the control of the stoichiometry is a key point. In case of a mixture of precursors, the $\mathrm{Sr} / \mathrm{Ti}$ ratio in solution has to be adjusted to get the correct films stoichiometry. Since the $\mathrm{Sr}$ and $\mathrm{Ti}$ precursors exhibit different decomposition yields, the composition of the film is different from the composition of the liquid. Another requirement for process purposes is that the process window (temperature, working pressure) is as large as possible. As shown in Fig. 5, the films composition strongly depends on the substrate's temperature (for a given liquid composition). On the contrary, by using the $\mathrm{Sr}_{2} \mathrm{Ti}_{2}(\mathrm{tmhd})_{4}\left(\mathrm{O}^{i} \mathrm{Pr}\right)_{8}$ heterometallic

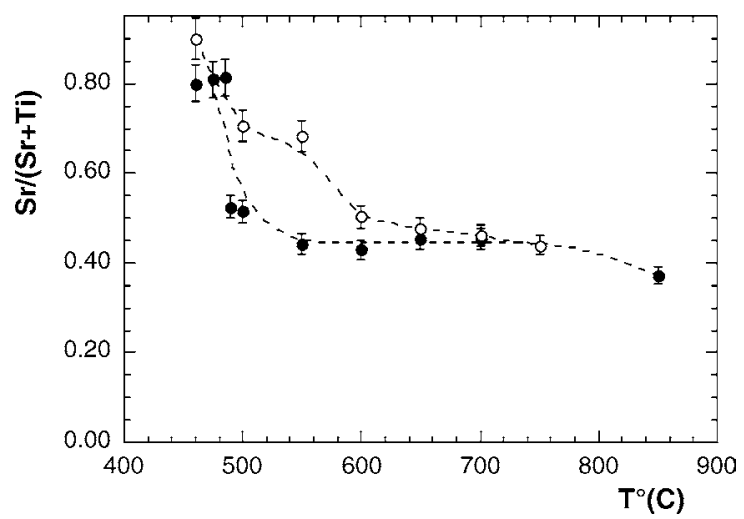

Fig. 5. Films overall composition determined from wavelength dispersion spectroscopy as a function of deposition temperature when using a mixture of precursors (open symbols) or the heterometallic precursor (closed symbols). precursor, the films composition remains constant in a quite large temperature range of $550{ }^{\circ} \mathrm{C}-750{ }^{\circ} \mathrm{C}$ (and unchanged in the pressure range of $266-666 \mathrm{~Pa}$ ). Another beneficial effect by using this heterometallic molecule is the lowering of the deposition temperature. With the mixture of precursors, the perovskite-type phase crystallises at temperature higher than $600^{\circ} \mathrm{C}$, whereas crystallisation occurs at $\sim 500^{\circ} \mathrm{C}$ with the heterometallic precursor (under $666 \mathrm{~Pa}$ ). In both cases the films are polycrystalline and textured. The texturation increases with decreasing pressure (from 666 down to $266 \mathrm{~Pa}$ ) with [ $\left[\begin{array}{lll}0 & 0 & 1\end{array}\right]$ axis perpendicular to the substrate's plane. It is optimal in the temperature range of $650-750{ }^{\circ} \mathrm{C}$. The films are not in plane oriented. Fig. 6 shows a typical microstructure as observed by TEM for a polycrystalline $\mathrm{SrTiO}_{3}$ film grown at $700^{\circ} \mathrm{C}$.

When deposition conditions are optimised for given working conditions, films are of equal quality (from electrical point of view) whatever the precursors mentioned above are used. $\mathrm{SrTiO}_{3}$ films of different thicknesses were prepared (4-220 nm). Fig. 7 shows the dielectric permittivity as a function of thickness. The permittivity was calculated from the effective permittivity value deduced from the maximum capacitance of the $C(V)$ curves in accumulation mode by taking into account the contribution of the interfacial layer. The
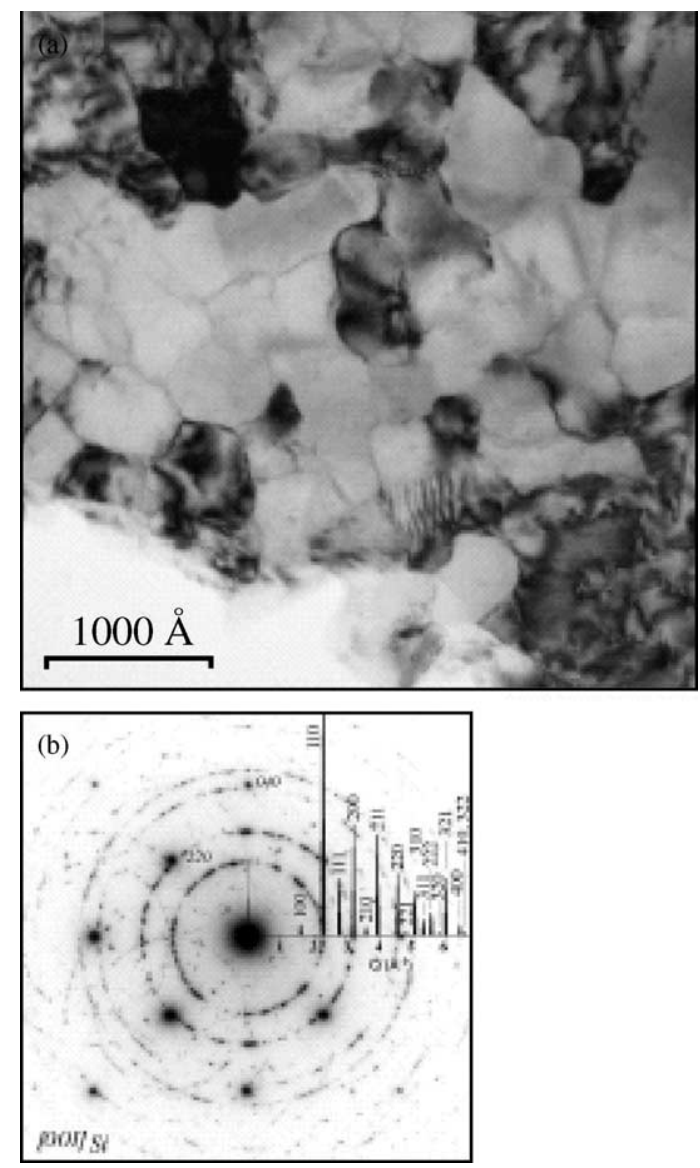

Fig. 6. (a) TEM bright field image and (b) corresponding diffraction electron pattern of a polycrystalline $\mathrm{SrTiO}_{3}$ film deposited on (l0 01$) \mathrm{Si} / \mathrm{SiO}_{2}$. 


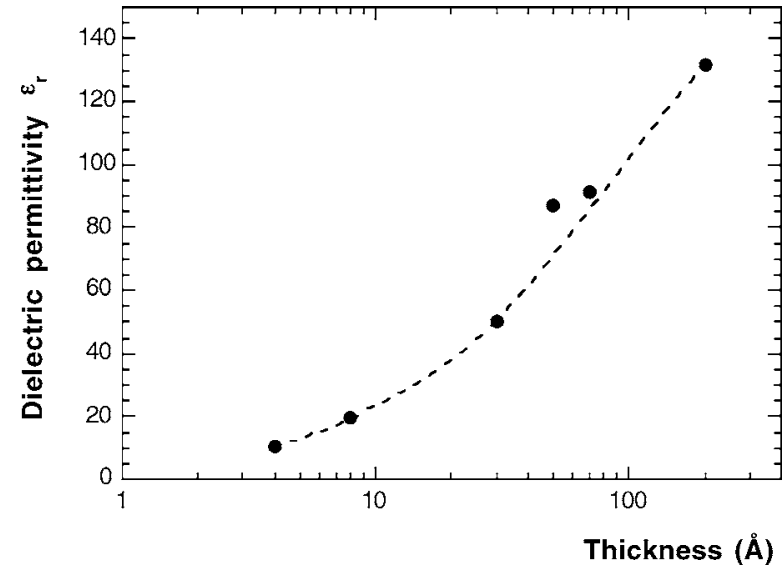

Fig. 7. Intrinsic dielectric permittivity of $\mathrm{SrTiO}_{3}$ films as a function of films thickness. It was calculated by taking into account the interfacial layer (permittivity of 3.9) contribution on the effective permittivity.

interfacial layer thickness was determined from TEM observations and its permittivity was estimated to be close to that of $\mathrm{SiO}_{2}$. There is a clear size effect, with a strong decrease of the permittivity with decreasing films thickness $(\varepsilon \sim 30$ for $t=10 \mathrm{~nm}$ and $\varepsilon \sim 100$ for $t=100 \mathrm{~nm}$ ). The lowest EOT obtained so far is of $1.36 \mathrm{~nm}$ with leakage current density of $10^{-2} \mathrm{~A} \mathrm{~cm}^{-2}$ at $1 \mathrm{~V}$ (for a physical thickness of $15.0 \mathrm{~nm}$ ). The obtained leakage current density represents a gain of about three orders of magnitude as compared to the value that would be obtained for the same $\mathrm{SiO}_{2}$ thickness. This result was obtained with a solution prepared from a mixture of precursors. Different transport mechanisms have been evidenced as a function of thickness [30]. The lowest leakage current density $\left(10^{-9} \mathrm{~A} \mathrm{~cm}^{-2}\right.$ at $\left.1 \mathrm{~V}\right)$ and lowest interfacial defects density $\left(D_{\text {it }}<10^{11} \mathrm{eV}^{-1} \mathrm{~cm}^{-2}\right)$ are obtained for films of thickness $\sim 30 \mathrm{~nm}$, in which transport mechanisms are governed by Schottky emission [30].

\section{Conclusion}

Both for $\mathrm{HfO}_{2}$ and $\mathrm{SrTiO}_{3}$ compounds, the choice of precursors is of outmost importance in determining the microstructure or process window (temperature, pressure) of the films grown by MOCVD. Low temperature-grown amorphous films are porous when prepared from $\mathrm{Hf}\left(\mathrm{O}^{t} \mathrm{Bu}\right)_{4}$ precursor, which is not the case when using $\mathrm{Hf}\left(\mathrm{O}^{t} \mathrm{Bu}\right)_{2}(\mathrm{mmp})_{2}$. At temperatures below $400^{\circ} \mathrm{C}$, the films are amorphous whereas they crystallise in the monoclinic structure for temperatures higher than $400{ }^{\circ} \mathrm{C}$. Amorphous films crystallise upon high-temperature annealing under $\mathrm{O}_{2}$ and it is accompanied by an increase of the interfacial layer thickness. Surface nitridation prior to deposition does not allow to limit this interfacial layer growth. Permittivity values of 14-19 are obtained, which is consistent with the monoclinic structure. Breakdown electrical field of $6 \mathrm{MV} \mathrm{cm}^{-1}$ and leakage current densities as low as $10^{-8} \mathrm{~A} \mathrm{~cm}^{-2}$ at $1 \mathrm{~V}$ are obtained. For $\mathrm{SrTiO}_{3}$ synthesis, the heterometallic precursor
$\mathrm{Sr}_{2} \mathrm{Ti}_{2}(\mathrm{tmhd})_{4}\left(\mathrm{O}^{i} \mathrm{Pr}\right)_{8}$ allows to crystallise the perovskitetype phase at lower temperature $\left(500^{\circ} \mathrm{C}\right)$ than the mixture of conventional precursors $\mathrm{Sr}(\mathrm{tmhd})_{2}+\mathrm{Ti}(\mathrm{tmhd})_{2}\left(\mathrm{O}^{i} \mathrm{Pr}\right)_{2}$ and films are free from carbonate phases. Moreover the films composition is constant in a wide temperature range of $550-750{ }^{\circ} \mathrm{C}$. The dielectric permittivity depends on the films thickness. An EOT of $1.36 \mathrm{~nm}$ and leakage current density of $10^{-2} \mathrm{~A} \mathrm{~cm}^{-2}$ are obtained, which is a promising result. Further optimisation of the film-substrate interface could allow to reduce the EOT below $1 \mathrm{~nm}$.

\section{Acknowledgments}

The results presented were obtained within the European IST "TOPS" project, the European MEDEA ${ }^{+}$T201 project and the Rhône-Alpes region "OXYDIEL" project.

\section{References}

[1] G. Wilk, R.M. Wallace, J.M. Anthony, J. Appl. Phys. 89 (2001) 5243.

[2] O.G. Vendik, L.T. Ter-Martirosyan, A.I. Dedyk, S.F. Karmanemko, R.A. Chakalov, Ferroelectrics 144 (1993) 33.

[3] D. Fuchs, C.W. Schneider, R. Schneider, H. Rietschel, J. Appl. Phys. 85 (1999) 7362.

[4] D.E. Kotecki, J.D. Baniecki, H. Shen, R.B. Laibowitz, k.L. Saenger, J.L. Lian, T.M. Shaw, S.D. Athavale, C. Cabral Jr., P.R. Duncombe, M. Gutsche, G. Kunkel, Y.-J. Park, Y.-Y. Wang, R. Wise, IBM J. Res. Develop. 43 (3) (1999).

[5] R.A. McKee, et al., Phys. Rev. Lett. 81 (1998) 3014.

[6] Z. Yu, et al., Mater. Res. Soc. Symp. Proc. 567 (1999) 415.

[7] K. Eisenbeiser, et al., Appl. Phys. Lett. 76 (2000) 1324.

[8] R.A. McKee, et al., Science 293 (2001) 468.

[9] J.P. Sénateur, R. Madar, F. Weiss, O. Thomas, A. Abrutis, French Patent FR 2,707,671 (1993), European Patent EP 730,671 (1994), US Patent US 945,162 (1999).

[10] C. Dubourdieu, J.P. Sénateur, F. Weiss, in: M. Guilloux-Viry, A. Perrin (Eds.), Crystal Growth in Thin Solid Films: Control of Epitaxy, 2002, p. 169, ISBN 81-7736-095-7.

[11] K.J. Choi, W.C. Shin, S.G. Yoon, J. Electrochem. Soc. 149 (3) (2002) F18.

[12] S.J. Lee, T.S. Jeon, D.L. Kwong, R. Clark, J. Appl. Phys. 92 (2002) 2807.

[13] S. Sayan, E. Garfunkel, S. Suzer, Appl. Phys. Lett. 80 (2002) 2135.

[14] F. Roussel, H. Roussel, M. Audier, C. Dubourdieu, J.-P. Sénateur, C. Jimenez, T.J. Leedham, H.O. Davies, A.C. Jones, B.J. O’Sullivan, M. Modreanu, P.K. Hurley, Q. Fang, I.W. Boyd, Electrochem. Soc. Proc. 2003-08 (2003) 907.

[15] N. Wu, Q. Zhang, C. Zhu, C.C. Yeo, S.J. Whang, D.S.H. Chan, M.F. Li, B.J. Cho, A. Chin, D.L. Kwong, A.Y. Du, C.H. Tung, N. Balasubramanian, Appl. Phys. Lett. 84 (2004) 3741.

[16] H. Kato, T. Nango, T. Miyagawa, T. Katakiri, K.S. Seol, Y. Ohki, J. Appl. Phys. 92 (2002) 1106.

[17] N. Rochat, K. Daberstrand, V. Cosnier, S. Zoll, P. Besson, U. Weber, Phys. Stat. Sol. (c) 0 (2003) 2961.

[18] M. Lee, Z.H. Lu, W.T. Ng, D. Landheer, X. Wu, S. Moisa, Appl. Phys. Lett. 83 (2003) 2638

[19] V.V. Afanas'ev, A. Stesmans, J. Appl. Phys. 95 (2004) 2518.

[20] P.A. Williams, J.L. Roberts, A.C. Jones, P.R. Chalker, N.L. Tobin, J.F. Bickley, H.O. Davies, L.M. Smith, T.J. Leedham, Chem. Vapor Depos. 8 (2002) 163. 
[21] K. Kukli, M. Ritala, M. Leskala, T. Sajavaara, J. Keinonen, A.C. Jones, J.L. Robersts, Chem. Vapor Depos. 9 (2003) 315.

[22] I. Baxter, S.R. Drake, M.B. Hursthouse, K.M. Abdul Malik, D.M.P. Mingos, J.C. Plakatouras, D.J. Otway, Polyhedron 17 (5/6) (1998) 625.

[23] A.I. Yanovskii, Z.A. Starikova, M.I. Yanovskaya, N.M. Kotova, N.Ya. Turova, Russ. J. Inorg. Chem. 48 (2003) 1320.

[24] C. Pettinari, F. Marchetti, R. Pettinari, V. Vertlib, A. Drozdov, I. Timokhin, S. Troyanov, Y.S. Min, D. Kim, Inorg. Chim. Acta 355 (2003) 157.

[25] S. Daniele, L.G. Hubert-Pfalzgraf, J.C. Daran, S. Halut, Polyhedron 13 (1994) 927.

[26] L. Hubert-Pfalzgraf, S. Daniele, J. Sol Gel Sci. Technol. 8 (1997) 49.
[27] D.A. Neumayer, E. Cartier, J. Appl. Phys. 90 (2001) 1801

[28] V. Cosnier, K. Dabertrand, S. Blonkowski, S. Lhostis, S. Zoll, Y. Morand, S. Descombes, B. Guillaumot, C. Hobbs, N. Rochat, G. Rolland, O. Renault, X. Garros, M. Cassé, J. Mitard, P. Lehnen, S. Miedl, J. Lindner, M. Schumacher, Atomic Vapour Deposition $\left(\mathrm{AVD}^{\mathrm{TM}}\right)$ Process for High Performance $\mathrm{HfO}_{2}$ Dielectrics Layers, in: Proceedings of the Materials Research Society Conference, San Francisco, 2004.

[29] B.J. O'Sullivan, P.K. Hurley, E. O'Connor, M. Modreanu, H. Roussel, C. Jimenez, C. Dubourdieu, M. Audier, J.P. Sénateur, J. Electrochem. Soc. 151 (8) (2004) 493.

[30] J. Legrand, S. Lhostis, Y. Chang, L. Militaru, C. Lamard, A. Sibai, L. Auvray, M. Audier, J.-P. Sénateur, C. Dubourdieu, F. Ducroquet, Microelectr. Eng. 7 (2004) 310. 